\title{
Synthesis and Crystal Structure of ( $\mu$-Acetato)bis( $\mu$-Alkoxo)dicobalt(II, III) Complex with an Unsymmetric Dinucleating Ligand
}

\author{
Naho Shinde, ${ }^{*}$ Ryunosuke Handa, ${ }^{*}$ Hideki Furutachi, $* * * \dagger$ Yoko SaKata, $* * *$ Shigehisa AKIne, $*, * *$ \\ Shuhei FuJINAMI,* and Masatatsu SuzUKI* \\ *Department of Chemistry, Division of Material Sciences, Graduate School of Natural Science and Technology, \\ Kanazawa University, Kakuma-machi, Kanazawa 920-1192, Japan \\ **WPI Nano Life Science Institute (WPI-NanoLSI), Kanazawa University, Kakuma-machi, Kanazawa 920-1192, \\ Japan
}

\begin{abstract}
The structure of the dinuclear $\mathrm{Co}(\mathrm{II}, \mathrm{III})$ mixed-valence complex $\left[\mathrm{Co}^{\mathrm{II}} \mathrm{Co}\right.$ III $\left.(\mathrm{tpdb})\left(\mathrm{CH}_{3} \mathrm{CO}_{2}\right)\left(\mathrm{CH}_{3} \mathrm{O}\right)\right]\left(\mathrm{ClO}_{4}\right)_{2}$. $0.75 \mathrm{CH}_{3} \mathrm{OH} \cdot 0.25 \mathrm{CH}_{3} \mathrm{CN}$ (1) was determined by X-ray crystallography, where tpdb is $N, N, N^{\prime}, N^{\prime}$-tetrakis(2-pyridylmethyl)1,4-diamino-2-butanolate. The compound crystallizes in the monoclinic space group, $P 2_{1} / \mathrm{c}$, with $a=10.4372(4), b=$ 27.8578(10), $c=13.5496(5) \AA, \beta=102.8116(10), Z=4, V=3841.6(2) \AA^{3}$. The $R 1[I>2 \sigma(I)]$ and $w R 2$ (all data) values are 0.0398 and 0.1035 , respectively, for all 6799 independent reflections. The complex has a ( $\mu$-acetato)bis $(\mu$-alkoxo)dicobalt(II, III) core structure.
\end{abstract}

(Received October 19, 2020; Accepted November 16, 2020; Published on web March 10, 2021)

The bimetallic active centers of metalloproteins exhibit versatile roles; model studies using simple dinuclear metal complexes are important in order to gain insight into the biological functions of such bimetallic cores. ${ }^{1-5}$ The end-off type dinucleating ligands, having a phenolic and alcoholic oxygen as an endogenous bridge, have been used for modeling carboxylate-bridged bimetallic active sites of metalloproteins. ${ }^{1-5}$ Previously, we reported on the synthesis and characterization of a peroxo complex, $\left[\mathrm{Co}^{\mathrm{III}}{ }_{2}(\mathrm{tpdb})\left(\mathrm{O}_{2}\right)\left(\mathrm{CH}_{3} \mathrm{CO}_{2}\right)\right]^{2+},{ }^{6}$ and a mixed-valence complex, $\left[\mathrm{Fe}^{\mathrm{II}} \mathrm{Fe}^{\mathrm{III}}(\mathrm{tpdb})\left(\mathrm{C}_{6} \mathrm{H}_{5} \mathrm{CO}_{2}\right)_{2}\right]^{2+},{ }^{7}$ having an unsymmetric dinucleating ligand with pyridyl groups (tpdb) as models for hemerythrin and purple acid phosphatase. In this paper, we report on the crystal structure of a dicobalt(II, III) mixed-valence complex, $\left[\mathrm{Co}^{\mathrm{II}} \mathrm{Co}\right.$ III $\left.(\mathrm{tpdb})\left(\mathrm{CH}_{3} \mathrm{CO}_{2}\right)\left(\mathrm{CH}_{3} \mathrm{O}\right)\right]-\left(\mathrm{ClO}_{4}\right)_{2} \cdot 0.75 \mathrm{CH}_{3} \mathrm{OH}$. $0.25 \mathrm{CH}_{3} \mathrm{CN}$ (1) (Fig. 1), which was obtained by an oxidative degradation of $\left[\mathrm{Co}_{2}{ }_{2}(\mathrm{tpdb})\left(\mathrm{CH}_{3} \mathrm{CO}_{2}\right)\right]^{2+}$ in methanol/acetonitrile at ambient temperature under air.

A mixture of $\mathrm{Co}\left(\mathrm{ClO}_{4}\right)_{2} \cdot 6 \mathrm{H}_{2} \mathrm{O}(0.366 \mathrm{~g}, 1.0 \mathrm{mmol})$ and $\mathrm{Htpdb}$ $(0.235 \mathrm{~g}, 0.5 \mathrm{mmol})$ in methanol/acetonitrile $(3: 1,12 \mathrm{~mL})$ was added to a methanol solution ( $5 \mathrm{~mL}$ ) containing $\mathrm{CH}_{3} \mathrm{CO}_{2} \mathrm{Na} \cdot 3 \mathrm{H}_{2} \mathrm{O}$

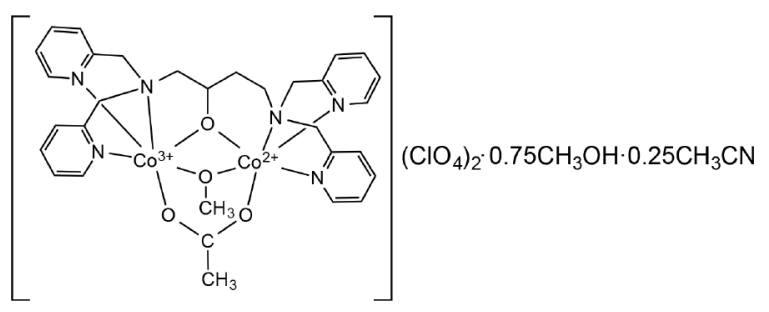

Fig. 1 Chemical diagram of $\left[\mathrm{Co}^{\mathrm{II}} \mathrm{Co}+\mathrm{III}(\mathrm{tpdb})\left(\mathrm{CH}_{3} \mathrm{CO}_{2}\right)\left(\mathrm{CH}_{3} \mathrm{O}\right)\right]-$ $\left(\mathrm{ClO}_{4}\right)_{2} \cdot 0.75 \mathrm{CH}_{3} \mathrm{OH} \cdot 0.25 \mathrm{CH}_{3} \mathrm{CN}(\mathbf{1})$.

$\dagger$ To whom correspondence should be addressed.

E-mail: h-furutachi@se.kanazawa-u.ac.jp
$(0.07 \mathrm{~g}, 0.5 \mathrm{mmol})$ and triethylamine $(69 \mu \mathrm{L}, 0.5 \mathrm{mmol})$ to give a dark-brown solution. Oxygen gas was bubbled for 5 min into the solution. The resulting dark-brown solution was allowed to stand for several weeks at ambient temperature under air to give single crystals of $\left[\mathrm{Co}^{\mathrm{II}} \mathrm{Co}^{\mathrm{III}}(\mathrm{tpdb})\left(\mathrm{CH}_{3} \mathrm{CO}_{2}\right)\left(\mathrm{CH}_{3} \mathrm{O}\right)\right]\left(\mathrm{ClO}_{4}\right)_{2}$. $0.75 \mathrm{CH}_{3} \mathrm{OH} \cdot 0.25 \mathrm{CH}_{3} \mathrm{CN}$ (1) suitable for X-ray crystallography. Yield: 0.28 g, $63 \%$ (Anal. Found: C, 41.20; H, 4.37; N, 9.28\%. Calcd for $\left[\mathrm{Co}^{\mathrm{II}} \mathrm{Co}^{\mathrm{III}}(\mathrm{tpdb})\left(\mathrm{CH}_{3} \mathrm{CO}_{2}\right)\left(\mathrm{CH}_{3} \mathrm{O}\right)\right]\left(\mathrm{ClO}_{4}\right)_{2} \cdot 1.5 \mathrm{H}_{2} \mathrm{O}$, $\mathrm{C}_{31} \mathrm{H}_{40} \mathrm{Cl}_{2} \mathrm{Co}_{2} \mathrm{~N}_{6} \mathrm{O}_{13.5}: \mathrm{C}, 41.30 ; \mathrm{H}, 4.47 ; \mathrm{N}, 9.32 \%$.). It was picked up from the solution by a loop on a hand-made cold copper plate mounted inside a liquid $\mathrm{N}_{2}$ Dewar vessel at $-80^{\circ} \mathrm{C}$; the loop was mounted on the diffractometer. X-ray diffraction measurements were made on a Bruker D8 VENTURE diffractometer $(\mathrm{Cu} \mathrm{K \alpha}$ radiation) at $90 \mathrm{~K}$. The structure was solved by a direct method (SHELXT) ${ }^{8}$ and expanded using a Fourier technique. The structure was refined by a full-matrix least-squares method by using SHELXL $2014^{9}$ (Yadokari-XG). ${ }^{10}$ All non-hydrogen atoms were refined with anisotropic displacement parameters. The hydrogen atoms were included using a riding model. For the disordered anion and solvent molecules, occupancy factors were refined using distance/ADP restraints. The crystal data are summarized in Table 1 .

The X-ray crystallography of $\mathbf{1}$ reveals that the asymmetric unit contains a complex cation $\left[\mathrm{Co}^{\mathrm{II}} \mathrm{Co}^{\mathrm{III}}(\mathrm{tpdb})\left(\mathrm{CH}_{3} \mathrm{CO}_{2}\right)\right.$ $\left.\left(\mathrm{CH}_{3} \mathrm{O}\right)\right]^{2+}$, two $\mathrm{ClO}_{4}^{-}$, and 0.75 methanol and 0.25 acetonitrile molecule (Fig. S1). An ORTEP drawing of the complex cation, $\left[\mathrm{Co}^{\mathrm{II}} \mathrm{Co}^{\mathrm{III}}(\mathrm{tpdb})\left(\mathrm{CH}_{3} \mathrm{CO}_{2}\right)\left(\mathrm{CH}_{3} \mathrm{O}\right)\right]^{2+}$ of $\mathbf{1}$, is shown in Fig. 2. Selected bond distances $(\AA)$ and angle $\left({ }^{\circ}\right)$ are given in Table 2 . The complex cation of $\mathbf{1}$ has distinct cobalt centers that are triply bridged by alkoxo oxygens of tpdp and methoxo, and acetate group as found for closely related dicobalt(II, III) mixedvalence complex $\left[\mathrm{Co}^{\mathrm{II}} \mathrm{Co}^{\mathrm{III}}(\mathrm{L})_{2}\left(\mathrm{CH}_{3} \mathrm{CO}_{2}\right)\left(\mathrm{CH}_{3} \mathrm{O}\right)_{2}\right]^{2+}$ (2) (L = $N$-methyl- $N, N$-bis(2-pyridylmethyl)amine). ${ }^{11} \quad$ The $\quad \mathrm{Co} 1 \cdots \mathrm{Co} 2$ separation is $2.9918 \AA$, which is slightly longer than that of 2 $(2.956 \AA)$. Both of the cobalt atoms in $\mathbf{1}$ have a distorted octahedral structure with an $\mathrm{N}_{3} \mathrm{O}_{3}$ donor set, where three 
Table 1 Crystal and experimental data

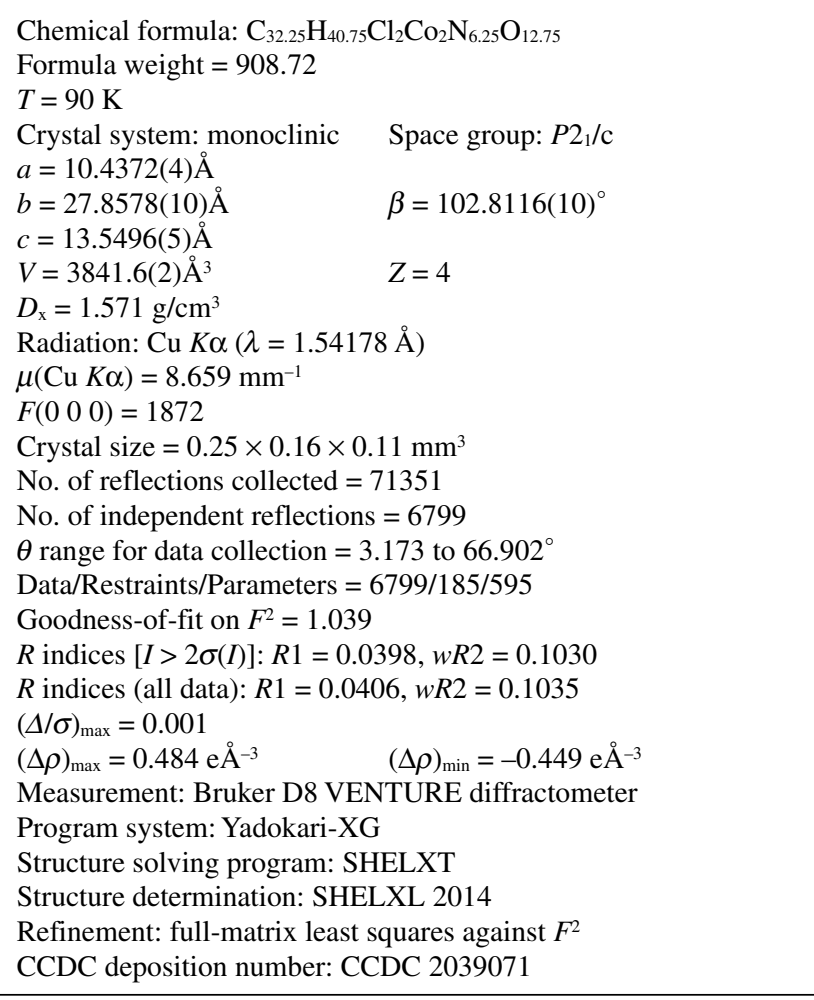

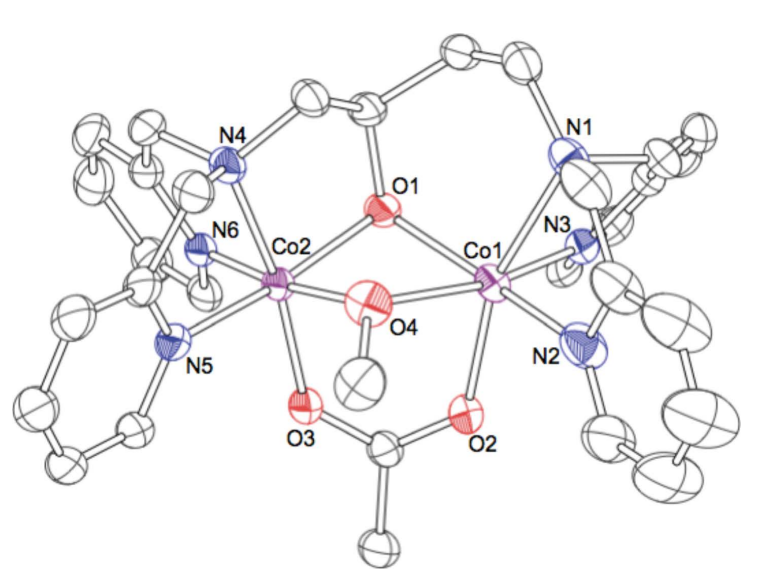

Fig. 2 ORTEP drawing of the complex cation, [Co ${ }^{\mathrm{II}} \mathrm{Co}^{\mathrm{III}}(\mathrm{tpdb})-$ $\left.\left(\mathrm{CH}_{3} \mathrm{CO}_{2}\right)\left(\mathrm{CH}_{3} \mathrm{O}\right)\right]^{2+}$ of $\mathbf{1}$, showing $50 \%$ probability ellipsoids. The hydrogen atoms are omitted for clarity.

nitrogen atoms of tpdb are in a facial array. The oxidation states of the cobalt centers are clearly distinguished by comparing the $\mathrm{Co}-\mathrm{O}$ and $\mathrm{Co}-\mathrm{N}$ bond distances. The average Co1-O (2.08 $\AA$ ) and Co1-N (2.12 $\AA$ ) bond distances are comparable to the Co ${ }^{\mathrm{II}}-\mathrm{O}(2.07 \AA)$ and $\mathrm{Co}^{\mathrm{II}}-\mathrm{N}(2.15 \AA)$ bonds of the six-coordinate high-spin cobalt(II) center in $2 .^{11}$ The average Co2-O (1.91 $⿱$ ) and $\mathrm{Co} 2-\mathrm{N}(1.96 \AA)$ bond distances are comparable to the $\mathrm{Co}^{\mathrm{III}}-\mathrm{O}(1.90 \AA)$ and $\mathrm{Co}^{\mathrm{III}}-\mathrm{N}(1.96 \AA)$ bonds of the six-coordinate low-spin cobalt(III) centers in 2 and $\left[\mathrm{Co}_{2}{ }_{2}(\mathrm{tpdb})\left(\mathrm{O}_{2}\right)-\right.$ $\left.\left(\mathrm{CH}_{3} \mathrm{CO}_{2}\right)\right]^{2+}$. ${ }^{6}$ The average $\mathrm{Co} 2-\mathrm{O}(1.91 \AA)$ and $\mathrm{Co} 2-\mathrm{N}(1.96 \AA)$ bond distances are substantially shorter than the average Co1-O $(2.08 \AA)$ and Co1-N $(2.12 \AA)$ bond distances, indicating that the oxidation state of the $\mathrm{Co} 1$ is divalent and the $\mathrm{Co} 2$ is trivalent.
Table 2 Selected bond distances $(\AA)$ and angle $\left({ }^{\circ}\right)$

\begin{tabular}{llll}
\hline Co1-O1 & $2.0182(18)$ & Co2-O1 & $1.9102(17)$ \\
Co1-O2 & $2.0636(19)$ & Co2-O3 & $1.9202(18)$ \\
Co1-O4 & $2.165(2)$ & Co2-O4 & $1.906(2)$ \\
Co1-N1 & $2.203(2)$ & Co2-N4 & $1.968(2)$ \\
Co1-N2 & $2.073(3)$ & Co2-N5 & $1.960(2)$ \\
Co1-N3 & $2.079(2)$ & Co2-N6 & $1.950(2)$ \\
Co1-.-Co2 & $2.9918(5)$ & & \\
Co1-O1-Co2 & $99.17 \quad(8)$ & Co1-O4-Co2 & $94.39 \quad(8)$ \\
\hline
\end{tabular}

Thus, 1 can be described as a localized mixed-valence complex as similar to $2 .{ }^{11}$ The $\mathrm{Co}-\mathrm{O}$ and $\mathrm{Co}-\mathrm{N}$ bond length differences for the high-spin Co1 vs the low-spin $\mathrm{Co} 2$ center in $\mathbf{1}$ are 0.17 and $0.16 \AA$, respectively, which are similar to those observed for the dicobalt(II, III) mixed-valence complexes. ${ }^{11,12}$ The preferential occupation of $\mathrm{CO}^{\text {II }}$ and $\mathrm{Co}^{\text {III }}$ in two distinct coordination sites of tpdb can be interpreted in terms of the chelate ring size effect of the bridging skeleton. It is well known that the electron donor ability of the five-membered chelate ring is stronger than that of the six-coordination chelate ring. Thus, the five-membered chelate ring site of tpdb prefers $\mathrm{Co}^{\mathrm{III}}$ ion. A similar observation was made for a mixed-valence complex, $\left[\mathrm{Fe}^{\mathrm{II}} \mathrm{Fe}^{\mathrm{III}}(\mathrm{tpdb})\left(\mathrm{C}_{6} \mathrm{H}_{5} \mathrm{CO}_{2}\right)_{2}\right]^{2+}$, ${ }^{2}$ where the $\mathrm{Fe}^{\mathrm{III}}$ ion resides in the five-membered chelate ring site of tpdb.

\section{Acknowledgements}

This work was supported by Grants-in-Aid for Scientific Research from the Ministry of Education, Culture, Sports, Science and Technology, Japan.

\section{Supporting Information}

A cif format file and Fig. S1. This material is available free of charge on the Web at http://www.jsac.or.jp/xraystruct/.

\section{References}

1. D. E. Fenton and H. Okawa, Chem. Ber., 1997, 130, 433.

2. M. Suzuki, H. Furutachi, and H. Okawa, Coord. Chem. Rev., 2000, 200, 105.

3. A. L. Gavrilova and B. Bosnich, Chem. Rev., 2004, 104, 349.

4. E. Y. Tshuva and S. J. Lippard, Chem. Rev., 2004, 104, 987.

5. A. J. Jasniewski and L. Que Jr., Chem. Rev., 2018, 118, 2554.

6. T. Kayatani, Y. Hayashi, M. Suzuki, and A. Uehara, Bull. Chem. Soc. Jpn., 1994, 67, 2980.

7. M. Suzuki, S. Fujinami, T. Hibino, H. Hori, Y. Maeda, A. Uehara, and M. Suzuki, Inorg. Chim. Acta, 1998, 283, 124.

8. G. M. Sheldrick, Acta Crystallogr., 2015, A71, 3.

9. G. M. Sheldrick, Acta Crystallogr., 2015, C71, 3.

10. C. Kabuto, S. Akine, T. Nemoto, and E. Kwon, J. Cryst. Soc. Jpn., 2009, 51, 218.

11. J. Luo, N. P. Rath, and L. M. Mirica, Inorg. Chem., 2011, 50,6152 .

12. P. Chaudhuri, J. Querbach, K. Wieghardt, B. Nuber, and J. Weiss, J. Chem. Soc. Dalton Trans., 1990, 271. 